VIANA CUSTÓDIO, André; DA ROSA MOREIRA, Rafael Bueno. Revitimização de crianças e adolescentes em inquirições judiciais e violência institucional. Revista Eletrônica Direito e Política, Programa de Pós-Graduação Stricto Sensu em Ciência Jurídica da UNIVALI, Itajaí, v.16, n.1, 10 quadrimestre de 2021. Disponível em: www.univali.br/direitoepolitica - ISSN 1980-7791

\title{
REVITIMIZAÇÃO DE CRIANÇAS E ADOLESCENTES EM INQUIRIÇÕES JUDICIAIS E VIOLÊNCIA INSTITUCIONAL
}

\author{
CHILDREN AND ADOLESCENTS REVICTIMIZATION IN JUDICIAL \\ INVESTIGATIONS AND INSTITUTIONAL VIOLENCE
}

\author{
André Viana Custódio ${ }^{1}$ \\ Rafael Bueno da Rosa Moreira 2
}

\section{RESUMO}

Analisou-se a revitimização de crianças e adolescentes violentadas sexualmente a partir da obrigatoriedade da inquirição em audiências judiciais, demonstrandose o marco teórico da proteção integral de crianças e adolescentes, especificando-se o enfrentamento da violência sexual e contextualizando-se a revitimização e violação de direitos em processos judiciais. Utilizou-se da técnica de pesquisa bibliográfica, a partir da análise de livros, artigos científicos, teses, dissertações e legislações, assim como de estudo de caso factual, por meio da análise de indicadores sobre violência sexual contra crianças e adolescentes. $O$ método de abordagem é dedutivo, partindo da análise das premissas gerais sobre o tema e indo especificando, e o método de procedimento é monográfico e o estatístico. Constatou-se que crianças e adolescentes vítimas de violência sexual são submetidas, muitas das vezes, a violência institucional e psicológica que levam a rememorar os fatos traumáticos quando de ações arbitrárias, agressivas, insensíveis e descapacitadas por parte de entes públicos durante a realização de inquirições judiciais, o que gera a revitimização e a violação de direitos.

PALAVRAS-CHAVE: adolescente; criança; infância; revitimização; violência sexual.

\footnotetext{
1 Pós-Doutor em Direito pela Universidade de Sevilha - Espanha, Mestre e Doutor em Direito pela Universidade Federal de Santa Catarina (UFSC), Coordenador Adjunto e Professor do Programa de Mestrado e Doutorado em Direito da Universidade de Santa Cruz do Sul (UNISC/Santa Cruz do Sul/RS/Brasil), Coordenador do Grupo de Estudos em Direitos Humanos de Crianças, Adolescentes e Jovens (GRUPECA/UNISC) e Pesquisador do Grupo de Pesquisa Políticas Públicas de Inclusão Social (UNISC). E-mail: andreviana.sc@gmail.com.

2 Doutor em Direito com Bolsa Prosuc Capes Modalidade II e Mestre em Direito pela Universidade de Santa Cruz do Sul (UNISC), integrante do Grupo de Estudos em Direitos Humanos de Crianças, Adolescentes e Jovens (GRUPECA/UNISC) e do Grupo de Pesquisa Políticas Públicas de Inclusão Social (UNISC). Professor do Curso de Graduação em Direito do Centro Universitário da Região da Campanha (URCAMP/Bagé/RS/Brasil) e Coordenador do Grupo de Pesquisas sobre Direitos Humanos e Políticas Públicas para Crianças e Adolescentes (GEDIHCA-URCAMP). Endereço eletrônico: rafaelbmoreira2@yahoo.com.br.
} 
VIANA CUSTÓDIO, André; DA ROSA MOREIRA, Rafael Bueno. Revitimização de crianças e adolescentes em inquirições judiciais e violência institucional. Revista Eletrônica Direito e Política, Programa de Pós-Graduação Stricto Sensu em Ciência Jurídica da UNIVALI, Itajaí, v.16, n.1, 10 quadrimestre de 2021. Disponível em: www.univali.br/direitoepolitica - ISSN 1980-7791

\begin{abstract}
Based on the compulsory examination as a witness in judicial hearings, the present paper analyses the revitalization of sexually abused children and adolescents, demonstrating the theoretical framework of comprehensive protection of children and adolescents and, at the same time, specifying the confrontation of sexual violence and contextualizing the revictimization and violation of rights in legal proceedings. The present research is based on the technique of bibliographic research from the analysis of books, scientific articles, theses, dissertations and legislations, as well as factual case studies, are used to analyze indicators on sexual violence against children and adolescents. The method of approach is deductive, from the analysis of the general premises on the subject to more specific papers about the topic. The used research methods are the monographic and the statistical procedure. It was found that arbitrary, aggressive, insensitive and disqualified actions by public entities during the conduct of inquiries put children and adolescents victims of sexual violence subjected to institutional and psychological violence that lead to the recall of traumatic events which leads to revictimization and violation of rights.
\end{abstract}

Keywords: adolescent; Child; Childhood; Revictimization; Sexual violence.

\title{
INTRODUÇÃO
}

A oitiva de crianças e adolescentes violentadas sexualmente em audiências leva a revitimização em decorrência da realização de interrogações que fazem com que a pessoa relembre os fatos, gerando a repetição do sofrimento por ações de iniciativa institucional. A ocorrência da violência estatal, de natureza moral e verbal, é oriunda da obrigatoriedade que é imposta a crianças e adolescentes serem inquiridas judicialmente quando desnecessário, o que ocorre devido a falta de sensibilidade e capacitação de agentes públicos que atuam no processo judicial no que tange ao tratamento adequado a infância, gerando-se, recorrentemente, violações de direitos humanos e fundamentais.

Para o desenvolvimento da abordagem, delimitou-se na análise da revitimização de crianças e adolescentes violentadas sexualmente a partir da obrigatoriedade da inquirição em audiências judiciais, especialmente quando isso seria desnecessário. É comum acontecer casos típicos de violência institucional que são decorrentes de falta de sensibilidade e de capacitação de agentes públicos para lidar com esses fatores, não sendo proporcionado o tratamento adequado e 
VIANA CUSTÓDIO, André; DA ROSA MOREIRA, Rafael Bueno. Revitimização de crianças e adolescentes em inquirições judiciais e violência institucional. Revista Eletrônica Direito e Política, Programa de Pós-Graduação Stricto Sensu em Ciência Jurídica da UNIVALI, Itajaí, v.16, n.1, 10 quadrimestre de 2021. Disponível em: www.univali.br/direitoepolitica - ISSN 1980-7791

humanitário a crianças e adolescentes que estão passando por um período traumático em consequência dos atos sofridos de violência sexual, o que ocasiona a violação de direitos humanos e fundamentais. O marco teórico para a realização da pesquisa é a teoria da proteção integral.

O objetivo geral da pesquisa é analisar a revitimização de crianças e adolescentes violentadas sexualmente a partir obrigatoriedade da inquirição em audiências judiciais. Para tanto, os objetivos específicos são: demonstrar o marco teórico da proteção integral de crianças e adolescentes; especificar a proteção jurídica aos direitos de crianças e adolescentes para o enfrentamento da violência sexual; e contextualizar a revitimização e violação de direitos inerentes à infância durante a inquirição de crianças e adolescentes em processos judiciais.

O tema se justifica pelo fato de que as revitimizações e violações de direitos de crianças e adolescentes decorrentes de oitivas em processos judiciais vem causando recorrentemente impactos negativos no desenvolvimento integral da infância pela violência gerada de forma institucionalizada a partir da insensibilidade e incapacidade no que diz respeito a preservação da vítima nos procedimentos judiciais.

O problema que orienta a pesquisa é como ocorrem violações de direitos que revitimizam crianças e adolescentes que foram violentadas sexualmente em inquirições judiciais?

O método de abordagem é dedutivo, a partir da análise das generalidades em relação ao tema e sendo abordadas, posteriormente, suas especificidades, e o método de procedimento é o monográfico e o estatístico. Utilizou-se da técnica de pesquisa bibliográfica, a partir da análise de livros, artigos científicos, teses, dissertações e legislações, assim como de estudo de caso factual, por meio da análise de indicadores sobre violência sexual contra crianças e adolescentes. 
VIANA CUSTÓDIO, André; DA ROSA MOREIRA, Rafael Bueno. Revitimização de crianças e adolescentes em inquirições judiciais e violência institucional. Revista Eletrônica Direito e Política, Programa de Pós-Graduação Stricto Sensu em Ciência Jurídica da UNIVALI, Itajaí, v.16, n.1, 10 quadrimestre de 2021. Disponível em: www.univali.br/direitoepolitica - ISSN 1980-7791

\section{MARCO TEÓRICO DA PROTEÇÃO INTEGRAL DE DIREITOS DA CRIANÇA E DO ADOLESCENTE}

A estruturação da proteção jurídica dos direitos da criança e do adolescente está consolidada desde a Constituição de República Federativa do Brasil, quando foram superadas concepções retrógradas e ultrapassadas embasadas na doutrina da situação irregular e suas características do século XIX que foram utilizadas na construção do Códigos de Menores de 1927 e de 1979. Tendo as reais necessidades em torno de crianças e adolescentes sido omitidas, deixando-se de se assegurar o desenvolvimento integral em vista das privações de direitos decorrentes da concepção de menoridade, assim como de seus decorrentes estigmas e prejuízos. Os Códigos de Menores propagavam a doutrina da situação irregular, sendo legislações que se preocupavam com o "menor" que se encontrava em situação irregular, ou seja, aquelas crianças e adolescentes que eram objeto para fins de assistência do Estado em decorrência da ação direita de Juízes de Menores, que seguiam a Política Nacional do Bem-Estar do Menor ${ }^{3}$.

No contexto da época eram reproduzidas condições discriminatórias sobre as diversidades de gênero, étnicas-raciais, classe social e geracional, mantendo-se condições de exclusão social, política e econômica. Os próprios aparelhos do Estado transformavam, eficientemente, crianças e adolescentes em situação de pobreza em "menores em situação de risco". As percepções sobre a infância tornavam relevante o que uma criança ou adolescente "não tinha e não era", por meio do reprodução de práticas autoritárias, antidemocráticas e não universalizadas, além de discriminatórias, redutoras, negativas e que legitimavam a exclusão social, havendo um constante e significativo movimento contrário ao reconhecimento e proteção aos direitos humanos e fundamentais, o que mantinha a submissão de crianças e adolescentes aos interesses adultocêntricos ${ }^{4}$.

\footnotetext{
${ }^{3}$ CUSTÓDIO, André Viana. Teoria da proteção integral: pressupostos para a compreensão do direito da criança e do adolescente. Revista do Direito: Revista do programa de pós-graduação do mestrado e doutorado, Santa Cruz do Sul, n. 29, p. 22-43, jan-jun. 2008, p. 23-25.

${ }^{4}$ CUSTÓDIO, André Viana. Teoria da proteção integral: pressupostos para a compreensão do direito da criança e do adolescente, p. 23-25.
} 
VIANA CUSTÓDIO, André; DA ROSA MOREIRA, Rafael Bueno. Revitimização de crianças e adolescentes em inquirições judiciais e violência institucional. Revista Eletrônica Direito e Política, Programa de Pós-Graduação Stricto Sensu em Ciência Jurídica da UNIVALI, Itajaí, v.16, n.1, 10 quadrimestre de 2021. Disponível em: www.univali.br/direitoepolitica - ISSN 1980-7791

As crianças e adolescentes que foram submetidas à doutrina da situação irregular eram as que cometiam atos infracionais ou que estavam excluídas socialmente. A condição de pobreza familiar era classificada como uma situação de irregularidade que traria risco para o desenvolvimento integral durante à infância, o que condicionava a atuação do Estado por meio de ações assistencialistas administradas pelos magistrados. Economicamente, o Estado era incapaz de minimizar a ocorrência da desigualdade social e de suas consequências, perpassando-se a visão de que a pobreza levava a situação irregular do "menor", pois as crianças e adolescentes em situação de pobreza ou de extrema pobreza geravam riscos para a vida em sociedade e necessitavam de acompanhamento individualizado do Estado $^{5}$.

O protagonismo dos movimentos sociais em prol da infância foram fundamentais para que fosse desenvolvida a perspectiva da proteção integral no período de redemocratização do Brasil que culminou com a Constituição da República Federativa do Brasil em 1988. O processo de rompimento do modelo autoritário de Estado do período ditatorial teve primordial participação popular. Dessa forma, houve a construção dos pressupostos básicos da teoria da proteção integral a partir de bases democráticas que deram prioridade ao respeito aos direitos humanos e fundamentais, a condição de cidadania, a condição de sujeito de direitos e garantias e a constitucionalização de direitos de crianças e adolescentes ${ }^{6}$.

O Direito da Criança e do Adolescente tem sua origem a partir do questionamento dos movimentos sociais indignados com a realidade da criança e do adolescente brasileiros, afrontados, em sua quase totalidade, da sua cidadania. Essa indignação tornava-se maior à medida em que se analisava o modo com que foram historicamente tratados pela legislação brasileira, ou seja, como meros objetos de intervenção, tutelados pela Lei e pela Justiça7.

\footnotetext{
5 CUSTÓDIO, André Viana. Teoria da proteção integral: pressupostos para a compreensão do direito da criança e do adolescente, p. 25-26.

${ }^{6}$ CUSTÓDIO, André Viana; VERONESE, Josiane Rose Petry. Trabalho Infantil Doméstico. São Paulo: Saraiva, 2013, p. 119-127.

7 VERONESE, Josiane Rose Petry. O Estatuto da Criança e do Adolescente: Um Novo Paradigma. In: VERONESE, Josiane Rose Petry; ROSSATO, Luciano Alves; LÉPORE, Paulo Eduardo

(Coordenadores). Estatuto da Criança e do Adolescente: 25 anos de desafios e conquistas. São Paulo: Saraiva, 2015, p. 01.
} 
VIANA CUSTÓDIO, André; DA ROSA MOREIRA, Rafael Bueno. Revitimização de crianças e adolescentes em inquirições judiciais e violência institucional. Revista Eletrônica Direito e Política, Programa de Pós-Graduação Stricto Sensu em Ciência Jurídica da UNIVALI, Itajaí, v.16, n.1, 10 quadrimestre de 2021. Disponível em: www.univali.br/direitoepolitica - ISSN 1980-7791

O Direito da Criança e do Adolescente foi instituído pela Constituição da República Federativa do Brasil, tendo sido estruturado democraticamente a partir de uma revolução teórica que assegurou a garantia da proteção integral desde uma perspectiva constitucionalizada, ocasionando-se o rompimento do que estava estabelecido na doutrina da situação irregular. A teoria da proteção integral busca a garantia de direitos, como sujeito e cidadão, à universalidade de crianças e adolescentes, bem como estabelece que deve se assegurar tratamento especializado em decorrência da condição peculiar de pessoa em desenvolvimento que é própria do período da infância e da adolescência, caracterizando-se por modificações de ordem física, educacional, intelectual, psicológica, cultural, social, e mental.

A teoria da proteção integral é embasada em princípios, direitos fundamentais e regras, que legitimam a concretização de direitos por meio da execução de políticas públicas no âmbito do Sistema de Garantia de Direitos da Criança e do Adolescente. O Direito da Criança e do Adolescente está estruturado a partir do olhar da infância, cabendo a teoria da proteção integral a função de realizar a sua interpretação8.

Atualmente, o Direito da Criança e do Adolescente está protegido desde o ponto de vista do ordenamento jurídico internacional, constitucional e infraconstitucional no Brasil, sendo composto por um conjunto de princípios, regras de direitos humanos e fundamentais ${ }^{9}$.

As bases teóricas que alicerçam esse ramo do direito trazem dificuldades para que sejam reproduzidas ideias ultrapassadas e que estão superadas cientificamente. A proteção integral aos direitos da criança e do adolescente está sustentada, especialmente, na Convenção sobre Direitos da Crianças da Organização das Nações Unidas, na Constituição da República Federativa do Brasil e no Estatuto da Criança e do Adolescente ${ }^{10}$.

\footnotetext{
8 CUSTÓDIO, André Viana. Teoria da proteção integral: pressupostos para a compreensão do direito da criança e do adolescente, p. 30-31.

${ }_{9}$ CUSTÓDIO, André Viana. Teoria da proteção integral: pressupostos para a compreensão do direito da criança e do adolescente, p. 33-34.

${ }^{10}$ VERONESE, Josiane Rose Petry. O Estatuto da Criança e do Adolescente: Um Novo Paradigma, p. 01-05.
} 
VIANA CUSTÓDIO, André; DA ROSA MOREIRA, Rafael Bueno. Revitimização de crianças e adolescentes em inquirições judiciais e violência institucional. Revista Eletrônica Direito e Política, Programa de Pós-Graduação Stricto Sensu em Ciência Jurídica da UNIVALI, Itajaí, v.16, n.1, 10 quadrimestre de 2021. Disponível em: www.univali.br/direitoepolitica - ISSN 1980-7791

No Brasil vigora a cultura adultocêntrica, impondo-se as crianças e adolescentes a submissão em relação aos adultos, que são o foco dos objetivos sociais e do Estado. A coisificação da infância é outro fenômeno complexo e prejudicial a crianças e adolescentes brasileiras, que ocorre pela não garantia da condição de sujeito de direitos, equiparando-as a objetos em decorrência do processo de mercantilização das relações sociais.

O adultocentrismo e a coisificação da infância são consideradas causas para a ocorrência da violência sexual contra crianças e adolescentes:

[...] todo ato ou omissão praticado por pais, parentes ou responsáveis contra crianças e/ou adolescentes que - sendo capaz de causar dano físico, sexual e/ou psicológico à vítima - implica, de um lado, uma transgressão do poder/dever de proteção do adulto e, de outro, uma coisificação da infância, isto é, uma negação do direito que crianças e adolescentes têm de ser tratados como sujeitos e pessoas em condição peculiar de desenvolvimento ${ }^{11}$.

Destaca-se que os adultos possuem responsabilidades de proteção à crianças e adolescentes, sejam eles familiares ou não. Entretanto, recorrentemente tal prerrogativa é violada, o que gera consequências negativas para o desenvolvimento integral de crianças e adolescentes.

A coisificação da infância é um fenômeno praticado por adultos que impõe ao período geracional da infância um processo de tratamento objetificado, olvidando-se da garantia legal da condição de sujeito de direitos. As crianças ou os adolescentes expostas a tais processos exploratórios são tratadas como "coisas", ou seja, um objeto que pertence a um "proprietário" que é adulto. Nessas situações, é comum a violação de direitos por práticas de violência sexual realizada pelo adulto que se intitula como detentor do poder de utilização de seu "objeto" 12.

\footnotetext{
${ }^{11}$ GUERRA, Viviane N. de Azevedo. Violência de pais contra filhos: A tragédia revisitada. São Paulo: Cortez, 2001, p. 32-33.

${ }^{12}$ CUSTÓDIO, André Viana; MOREIRA, Rafael Bueno da Rosa. Exploração Sexual Comercial de

Crianças e Adolescentes: Reflexões Contemporâneas no Contexto do Brasil, da Argentina e do Uruguai. Curitiba: Multideia, 2015, p. 80-85.
} 
VIANA CUSTÓDIO, André; DA ROSA MOREIRA, Rafael Bueno. Revitimização de crianças e adolescentes em inquirições judiciais e violência institucional. Revista Eletrônica Direito e Política, Programa de Pós-Graduação Stricto Sensu em Ciência Jurídica da UNIVALI, Itajaí, v.16, n.1, ${ }^{\circ}$ quadrimestre de 2021. Disponível em: www.univali.br/direitoepolitica - ISSN 1980-7791

Já em se expondo sobre o adultocentrismo, há pensamento discriminatório próprio de "inferiorização" em relação à crianças e adolescentes, o que os coloca em condição de submissão frente aos adultos. A centralização das relações sociais é condicionada aos adultos, desconsiderando-se o período geracional da infância em vista de serem considerados como pessoas com menos direitos e garantias em decorrência de sua desimportância, dispensando-se a garantia de direitos de crianças e adolescentes, o que potencializa a possibilidade de violência sexual ${ }^{13}$.

A estruturação de uma teoria para a infância traz a perspectiva de consolidação de alicerces para que se modifique a atual realidade violenta contra crianças e adolescentes que é caracterizada por formas de opressão, submissão e discriminação. Uma teoria proporciona o desenvolvimento de interrogações e questionamentos sobre as imposições ideológicas reproduzidas na sociedade, visando o seu rompimento a partir da interpretação do direito em prol da emancipação de crianças e adolescentes ${ }^{14}$.

\section{PROTEÇÃO JURÍDICA AOS DIREITOS DA CRIANÇA E DO ADOLESCENTE PARA O ENFRENTAMENTO DA VIOLÊNCIA SEXUAL}

O Brasil vem consolidando proteção jurídica aos direitos da criança e do adolescentes a partir de sua redemocratização no ano de 1988. A Constituição da República Federativa do Brasil, o Estatuto da Criança e do Adolescente, a Convenção sobre Direitos da Criança da Organização das Nações Unidas e a Convenção 182 da Organização Internacional do Trabalho, são importantes legislações protetivas aos direitos de crianças e adolescentes, assim como mecanismos jurídicos que embasam o enfrentamento da violência sexual.

A sistematização da proteção aos direitos da criança e do adolescente no Brasil foi influenciada pelas Convenções Internacionais que tratam sobre direitos

\footnotetext{
13 VERONESE, Josiane Rose Petry. O Estatuto da Criança e do Adolescente: Um Novo Paradigma, p. 32-33.

${ }^{14}$ BUSTELO, Eduardo S. El recreo de la infancia: Argumentos para otro comienzo. Buenos Aires: Siglo Veintiuno Editores, 2011, p. 138-144.
} 
VIANA CUSTÓDIO, André; DA ROSA MOREIRA, Rafael Bueno. Revitimização de crianças e adolescentes em inquirições judiciais e violência institucional. Revista Eletrônica Direito e Política, Programa de Pós-Graduação Stricto Sensu em Ciência Jurídica da UNIVALI, Itajaí, v.16, n.1, 10 quadrimestre de 2021. Disponível em: www.univali.br/direitoepolitica - ISSN 1980-7791

humanos, especialmente a partir da ratificação pelo Decreto no 99.710, de 21 de novembro de 1990, da Convenção sobre Direitos da Criança da Organização das Nações Unidas, que é considerada a principal garantia de direitos humanos de crianças e adolescentes no âmbito mundial ${ }^{15}$.

Os direitos estabelecidos na Convenção sobre Direitos da Criança da Organização das Nações Unidas são inerentes à universalidade de crianças e adolescentes, devendo ser assegurados de forma igualitária:

Artigo 20. 1. Os Estados Partes respeitarão os direitos enunciados na presente Convenção e assegurarão sua aplicação a cada criança sujeita à sua jurisdição, sem distinção alguma, independentemente de raça, cor, sexo, idioma, crença, opinião política ou de outra índole, origem nacional, étnica ou social, posição econômica, deficiências físicas, nascimento ou qualquer outra condição da criança, de seus pais ou de seus representantes legais ${ }^{16}$.

A Convenção sobre os Direitos da Criança protege contra a violência sexual desde a perspectiva internacional, asseverando: a proteção contra qualquer forma de castigo ou de discriminação (art. 20); a proteção do bem-estar social (art. $3^{\circ}$ ); os direitos à saúde e à segurança (art. 30, 24 e 25); os direitos ao desenvolvimento e à vida (art. 60); o direito a convivência familiar harmônica (art. 90); o direito à liberdade de expressão (art. 13); o direito à educação gratuita e acessível na idade certa (art. 18 e 28); a proteção contra todas as formas de violência física ou mental (art. 19); o direito ao descanso e ao lazer (art. 31); o direito ao não trabalho, a proteção contra a exploração econômica e o direito ao trabalho regular, conforme as condições pertinentes à idade (art. $32)^{17}$.

Reafirma-se que a Convenção Internacional dos Direitos da Criança de 1989 previu a possibilidade de os Estados-partes investirem em políticas públicas sempre que for necessário ao fiel cumprimento dos direitos fundamentais dispostos no tratado. Que estas políticas atendam e proporcionem melhores condições de vida, melhores condições de

15 ONU. Convenção sobre os Direitos das Crianças. 1989. Disponível em:

http://www.planalto.gov.br/ccivil_03/decreto/1990-1994/D99710.htm. Acesso em: 26 fev. 2020.

16 ONU. Convenção sobre os Direitos das Crianças.

17 ONU. Convenção sobre os Direitos das Crianças. 
VIANA CUSTÓDIO, André; DA ROSA MOREIRA, Rafael Bueno. Revitimização de crianças e adolescentes em inquirições judiciais e violência institucional. Revista Eletrônica Direito e Política, Programa de Pós-Graduação Stricto Sensu em Ciência Jurídica da UNIVALI, Itajaí, v.16, n.1, 10 quadrimestre de 2021. Disponível em: www.univali.br/direitoepolitica - ISSN 1980-7791

desenvolvimento, sadio e harmonioso, e que zelem pelo cumprimento integral dos direitos inerentes à fase da infância. Que haja um reordenamento estratégico no campo das políticas públicas que incluam verdadeiramente as crianças, os adolescentes e suas famílias ${ }^{18}$.

As convenções internacionais têm como característica impactar positivamente a legislação dos Estados Membros da organização que a produz, o que gera reflexos na construção e desenvolvimento de sistemas de políticas públicas com o objetivo de realização do pactuado no âmbito internacional ${ }^{19}$. As convenções internacionais auxiliaram na consolidação do ordenamento jurídico e na estruturação de políticas públicas no Brasil, possibilitando instrumentos de enfrentamento de todas as formas de violência contra crianças e adolescentes.

O artigo 227 da Constituição da República Federativa do Brasil estabelece os direitos fundamentais da criança e do adolescente, assegura os princípios da proteção integral, da tríplice responsabilidade compartilhada e da prioridade absoluta, bem como busca a colocação de crianças e adolescentes a salvo de todas as formas de negligência, discriminação, exploração, violência, crueldade e opressão, sendo o principal dispositivo jurídico destinado à infância no país ${ }^{20}$ :

Art. 227 - É dever da família, da sociedade e do Estado assegurar à criança, ao adolescente e ao jovem, com absoluta prioridade, o direito à vida, à saúde, à alimentação, à educação, ao lazer, à profissionalização, à cultura, à dignidade, ao respeito, à liberdade e à convivência familiar e comunitária, além de colocá-los a salvo de toda forma de negligência, discriminação, exploração, violência, crueldade e opressão ${ }^{21}$.

A proteção integral também está assegurada no artigo $1^{\circ}$ do Estatuto da Criança e do Adolescente: "Esta Lei dispõe sobre a proteção integral à criança e ao

\footnotetext{
18 LIMA, Fernanda da Silva. Crise humanitária internacional e os direitos das crianças migrantes ou refugiadas: uma análise da opinião consultiva no 21 da Corte Interamericana de Direitos Humanos. Revista do Direito: Revista do Programa de Pós-graduação do Mestrado e Doutorado, Santa Cruz do Sul, v.1, n. 51, p. 87-107, jan./abr. 2017, p. 91.

19 REIS, Suzéte da Silva. Educação em Direitos Humanos: Perspectivas de promoção e defesa dos direitos das crianças e adolescentes. In: PES, João Hélio Ferreira (coordenador). Direitos
}

Humanos: Crianças e Adolescentes. Curitiba: Juruá, 2010, p. 152.

20 BRASIL. Constituição da República Federativa do Brasil. 1988. Disponível em:

http://www.planalto.gov.br/ccivil_03/constituicao/constitui\%C3\%A7ao.htm. Acesso em: 25 fev. 2020.

${ }^{21}$ BRASIL. Constituição da República Federativa do Brasil. 
VIANA CUSTÓDIO, André; DA ROSA MOREIRA, Rafael Bueno. Revitimização de crianças e adolescentes em inquirições judiciais e violência institucional. Revista Eletrônica Direito e Política, Programa de Pós-Graduação Stricto Sensu em Ciência Jurídica da UNIVALI, Itajaí, v.16, n.1, 10 quadrimestre de 2021. Disponível em: www.univali.br/direitoepolitica - ISSN 1980-7791

adolescente". Assim como, garante-se a proteção integral de crianças e adolescentes mediante tríplice responsabilidade compartilhada e com prioridade absoluta, de acordo com o estatuído no seu artigo 4022.

O artigo 40, praticamente reproduziu em sua integralidade o estabelecido no artigo 227 da Constituição da República Federativa do Brasil, disciplinando os princípios da proteção integral, da tríplice responsabilidade compartilhada e da prioridade absoluta, com o intuito auxiliar na efetivação de direitos fundamentais protegidos juridicamente:

Art. 40. É dever da família, da comunidade, da sociedade em geral e do poder público assegurar, com absoluta prioridade, a efetivação dos direitos referentes à vida, à saúde, à alimentação, à educação, ao esporte, ao lazer, à profissionalização, à cultura, à dignidade, ao respeito, à liberdade e à convivência familiar e comunitária.

Parágrafo único. A garantia de prioridade compreende:

a) primazia de receber proteção e socorro em quaisquer circunstâncias;

b) precedência de atendimento nos serviços públicos ou de relevância pública;

c) preferência na formulação e na execução das políticas sociais públicas;

d) destinação privilegiada de recursos públicos nas áreas relacionadas com a proteção à infância e à juventude ${ }^{23}$.

O Estatuto da Criança e do Adolescente prevê a proteção aos Direitos Fundamentais de crianças e adolescentes em título próprio, estabelecendo: o direito à dignidade, à liberdade ou ao respeito; o direito à profissionalização; o direito à vida e à saúde; o direito à educação, à cultura, ao esporte e ao lazer; direito à convivência familiar e comunitária; à proteção contra qualquer forma de discriminação, violência, opressão e crueldade, dentre outros que podem ser

22 BRASIL. Estatuto da Criança e do Adolescente. 1990. Disponível em: http://www.planalto.gov.br/ccivil_03/leis//8069compilado.htm. Acesso em: 25 fev. 2020.

23 BRASIL. Estatuto da Criança e do Adolescente. 
VIANA CUSTÓDIO, André; DA ROSA MOREIRA, Rafael Bueno. Revitimização de crianças e adolescentes em inquirições judiciais e violência institucional. Revista Eletrônica Direito e Política, Programa de Pós-Graduação Stricto Sensu em Ciência Jurídica da UNIVALI, Itajaí, v.16, n.1, 10 quadrimestre de 2021. Disponível em: www.univali.br/direitoepolitica - ISSN 1980-7791

afetados com a ocorrência da violência sexual ${ }^{24}$. Tais proteções jurídicas tendem a ser violadas com práticas de violência sexual.

A proteção jurídica de direitos no patamar constitucional, infraconstitucional e internacional são importantes avanços no enfrentamento da violência sexual contra crianças e adolescentes. Para tanto, busca-se que o rumo das relações sociais em torno da infância no Brasil sejam em direção a uma concepção de tolerância e não violência, que se dará mediante a primazia do cumprimento do estabelecido juridicamente num viés solidário e responsável.

Primeiro de tudo nos vem ao encontro, legado por séculos de cruéis guerras de religião, o ideal da tolerância. Se hoje existe uma ameaça à paz mundial, esta vem ainda uma vez do fanatismo, ou seja, da crença cega na própria verdade e na força capaz de impô-la. Inútil dar exemplos: podemos encontrá-los a cada dia diante dos olhos. Em segundo lugar, temos 0 ideal da não-violência: jamais esqueci 0 ensinamento de Karl Popper segundo o qual o que distingue essencialmente um governo democrático de um nãodemocrático é que apenas no primeiro os cidadãos podem livrar-se de seus governantes sem derramamento de sangue [...] Apenas onde essas regras são respeitadas 0 adversário não é mais um inimigo (que deve ser destruído), mas um opositor que amanhã poderá ocupar o nosso $\operatorname{lugar}^{25}$.

A tolerância e a não violência necessitam são condições a ser alcançadas para possibilitar o convívio pacífico entre a heterogeneidade dos grupos sociais. Nesse sentido, há uma complexidade de fenômenos que devem ser observados para que se possa atentar aos direitos e condições de cidadania de uma diversidade de pessoas, como é o caso de crianças e adolescentes ${ }^{26}$.

O ideal de cidadania é outro fator que se relaciona ao respeito às diversidades, devendo se primar em busca de modelo social pacífico e não violento:

Ser ciudadano, no es aborrecer a ninguno de sus conciudadanos sino respetar a todos, cualesquiera que sean sus diferencias de cultura, de religión, de opinión o de

\footnotetext{
24 BRASIL. Estatuto da Criança e do Adolescente.

25 BOBBIO, Norberto. O futuro da democracia. Traduzido por: Marco Aurélio Nogueira. Rio de Janeiro: Paz e Terra, 1999, p. 39.

26 LAPIERRE, Jean-William. Qué es ser ciudadano. Madrid: Biblioteca Nueva, 2003, p. 93-106.
} 
VIANA CUSTÓDIO, André; DA ROSA MOREIRA, Rafael Bueno. Revitimização de crianças e adolescentes em inquirições judiciais e violência institucional. Revista Eletrônica Direito e Política, Programa de Pós-Graduação Stricto Sensu em Ciência Jurídica da UNIVALI, Itajaí, v.16, n.1, 10 quadrimestre de 2021. Disponível em: www.univali.br/direitoepolitica - ISSN 1980-7791

interés, abreviando, respetar en ellos los derechos del hombre y rechazar todo lo que podría justificar el crimen contra la humanidad ${ }^{27}$.

O ordenamento jurídico nacional estabeleceu responsabilidades compartilhadas ao Estado, família, comunidade e sociedade em geral no que diz respeito a proteção aos direitos da criança e do adolescente. Estabelece o princípio da tríplice responsabilidade compartilhada, onde todas essas instituições são responsáveis pelas ações em prol da garantia do desenvolvimento integral no período da infância e do enfrentamento de todas as formas de violência contra crianças e adolescentes, atuando como protagonistas notificando casos identificados no contexto sociais.

O princípio da prioridade absoluta visa assegurar a efetivação prioritária de direitos estabelecidos no ordenamento jurídico constitucional e infraconstitucional em prol da proteção integral, sendo assegurado pelo artigo 40 do Estatuto da Criança e do Adolescente ${ }^{28}$.

O Brasil reforçou o compromisso internacional em relação ao enfrentamento de todas as formas de violências sexual de crianças e adolescentes a partir da ratificação da Convenção sobre os Direitos da Criança da Organização das Nações Unidas e da Convenção 182 da Organização Internacional do Trabalho, que trata das ações imediatas para o enfrentamento das piores formas de trabalho infantil, dentre elas a exploração sexual comercial. Para tanto, obriga-se a estabelecer proteção jurídica contra a violência sexual no período da infância e de instituir políticas públicas com ações estratégicas.

A Convenção sobre Direitos das Crianças, em seu artigo 34, trata do comprometimento dos Estados-partes que ratificarem a Convenção em proteger as crianças e adolescentes contra toda forma de violência sexual:

Art. 34. Os Estados Partes se comprometem a proteger a criança contra todas as formas de exploração e abuso sexual. Nesse sentido, os Estados Partes tomarão, em

27 LAPIERRE, Jean-William. Qué es ser ciudadano, p. 207.

28 BRASIL. Estatuto da Criança e do Adolescente. 1990. 
VIANA CUSTÓDIO, André; DA ROSA MOREIRA, Rafael Bueno. Revitimização de crianças e adolescentes em inquirições judiciais e violência institucional. Revista Eletrônica Direito e Política, Programa de Pós-Graduação Stricto Sensu em Ciência Jurídica da UNIVALI, Itajaí, v.16, n.1, 10 quadrimestre de 2021. Disponível em: www.univali.br/direitoepolitica - ISSN 1980-7791

especial, todas as medidas de caráter nacional, bilateral e multilateral que sejam necessárias para impedir:

a) o incentivo ou a coação para que uma criança se dedique a qualquer atividade sexual ilegal;

b) a exploração da criança na prostituição ou outras práticas sexuais ilegais;

c) a exploração da criança em espetáculos ou materiais pornográficos ${ }^{29}$.

O artigo 39 demonstra que cabe aos Estados-membros executar todas as medidas necessárias para a recuperação física e psicológica, bem como a inclusão social de crianças e adolescentes que forem vitimadas por práticas de violência. Destaca, também, a necessidade de que sejam adotadas medidas que protejam os direitos à saúde e à assistência social destinadas a infância, tendo por finalidade a restituição de direitos violados e garantia do desenvolvimento integral em sua multidimensionalidade se atentando para a condição de dignidade humana ${ }^{30}$.

Já o artigo 19 traz a obrigação dos Estados-partes em adotar todas as medidas, de ordem social, administrativa, legislativa, política e educacional, com o fulcro de proteção de crianças e adolescentes contra todos os tipos de violência, inclusive as de natureza sexual ${ }^{31}$.

A Convenção 182 da Organização Internacional do Trabalho, que dispõe sobre a proibição das piores formas de trabalho infantil e ação imediata para sua eliminação, estipula preceitos que objetivam a realização de ações em prol da erradicação de exploração sexual comercial de crianças e adolescentes, uma modalidade de violência sexual com cunho de econômico exploratório. A prioridade de enfrentamento a tal forma de trabalho infantil decorre dos seus significativos prejuízos para o desenvolvimento integral da pessoa humana. A Convenção 182 foi ratificada no Brasil pelo Decreto n. 3.597, de 12 de setembro de 2000, prevendo em seu artigo 3 queo: "Para efeitos da presente Convenção, a expressão "as piores formas de trabalho infantil" abrange: [...] b) a utilização, o

\footnotetext{
29 ONU. Convenção sobre os Direitos das Crianças. 1989.

30 ONU. Convenção sobre os Direitos das Crianças. 1989.

31 ONU. Convenção sobre os Direitos das Crianças. 1989.
} 
VIANA CUSTÓDIO, André; DA ROSA MOREIRA, Rafael Bueno. Revitimização de crianças e adolescentes em inquirições judiciais e violência institucional. Revista Eletrônica Direito e Política, Programa de Pós-Graduação Stricto Sensu em Ciência Jurídica da UNIVALI, Itajaí, v.16, n.1, 10 quadrimestre de 2021. Disponível em: www.univali.br/direitoepolitica - ISSN 1980-7791

recrutamento ou a oferta de crianças para a prostituição, a produção de pornografia ou atuações pornográficas; $[\ldots]^{\prime \prime 32}$.

O ordenamento jurídico brasileiro consolidou proteção jurídica adequada ao enfrentamento da violência sexual contra crianças e adolescentes por meio da promulgação da Constituição da República Federativa do Brasil, das ratificações da Convenção sobre Direitos da Criança da Organização das Nações Unidas e da Convenção 182 da Organização Internacional do Trabalho, e da instituição do Estatuto da Criança e do Adolescente. O desafio atual é a ampliação dos níveis de efetividade da legislação a partir da execução de políticas públicas, o que demanda estruturação de órgãos responsáveis, planejamento de ações estratégicas e capacitação de pessoal. A violência sexual contra crianças e adolescentes necessita de enfrentamento a partir de uma diversidade de políticas públicas intersetoriais e articuladas, com atribuições de responsabilidade de ações destinadas a crianças e adolescentes por parte das políticas públicas de proteção, atendimento, justiça e promoção de direitos.

\section{CONTEXTO DA REVITIMIZAÇÃO E VIOLAÇÃO DE DIREITOS INERENTES À INFÂNCIA NAS INQUIRIÇÕES DE CRIANÇAS E ADOLESCENTES}

O enfrentamento a violência sexual que assola crianças e adolescentes, violando direitos humanos e fundamentais, tem por finalidade a garantia do desenvolvimento integral de crianças e adolescentes, que ocorre em razão da situação peculiar de pessoa em desenvolvimento e da necessidade de proteções para a garantia do processo de formação nas dimensões físicas, psicológicas, mentais, socioculturais, morais, intelectuais e biológicas ${ }^{33}$.

\footnotetext{
32 OIT. Convenção 182 sobre a proibição das piores formas de trabalho infantil e ação imediata para sua eliminação. 1999. Disponível em:

http://www.ilo.org/public/spanish/standards/relm/ilc/ilc87/com-chic.htm. Acesso em: 26 fev. 2020.

33 CUSTÓDIO, André Viana; MOREIRA, Rafael Bueno da Rosa. Exploração Sexual Comercial de

Crianças e Adolescentes: Reflexões Contemporâneas no Contexto do Brasil, da Argentina e do Uruguai, p. 87-88.
} 
VIANA CUSTÓDIO, André; DA ROSA MOREIRA, Rafael Bueno. Revitimização de crianças e adolescentes em inquirições judiciais e violência institucional. Revista Eletrônica Direito e Política, Programa de Pós-Graduação Stricto Sensu em Ciência Jurídica da UNIVALI, Itajaí, v.16, n.1, 10 quadrimestre de 2021. Disponível em: www.univali.br/direitoepolitica - ISSN 1980-7791

A garantia dos direitos de cidadania à criança e ao adolescente é crucial em prol da não violência nas mais diversas relações sociais, reconhecendo-se concepções humanitárias. Adota-se, no contexto da presente abordagem, o conceito de cidadania de Marshall:

Chamarei estas três partes, ou elementos, de civil, política e social. O elemento civil é composto dos direitos necessários à liberdade individual - liberdade de ir e vir, liberdade de imprensa, pensamento e fé, direito à propriedade e de concluir contratos válidos e o direito à justiça [...] Por elemento político se deve entender o direito de participar do exercício do poder político, como um membro de um organismo investido da autoridade política ou como um eleitor dos membros de tal organismo [...] O elemento social se refere a tudo o que vai desde o direito a um mínimo de bem-estar econômico e segurança ao direito de participar, por completo, na herança social e levar a vida de um ser civilizado de acordo com os padrões que prevalecem na sociedade. As instituições mais intimamente ligadas com ele são o sistema educacional e os serviços sociais ${ }^{34}$.

Nesse viés, evidencia-se que os direitos sociais são elementares para o exercício de uma cidadania plena, o que ocorre em conjunto com as garantias políticas e civis. E o respeito à condição de sujeito de direitos, com garantias de um rol de direitos humanos e fundamentais, é fundamental para as relações sociais por meio de uma concepção humanitária ${ }^{35}$.

A compreensão e aplicação do conceito de cidadania não se restringe à consciência nacional, necessitando estar em consonância com os problemas humanitários do país, do continente e do planeta. Portanto, o senso de solidariedade e de responsabilidade são basilares para o exercício da cidadania. O sujeito é o centro das relações sociais e o produtor do conhecimento, sendo o produtor de linguagem e cultura para a humanidade, que deve ser de tolerância, paz e não violência ${ }^{36}$.

\footnotetext{
34 MARSHALL, T.H. Cidadania, classe social e status. Zahar Editores: Rio de Janeiro, 1967, p. 63-64.

35 MARSHALL, T.H. Cidadania, classe social e status, 1967, p. 73-79.

36 MORIN, Edgar. A cabeça bem-feita: repensar a reforma, reformar o pensamento. Rio de Janeiro: Bertrand Brasil, 2001, p. 65-97.
} 
VIANA CUSTÓDIO, André; DA ROSA MOREIRA, Rafael Bueno. Revitimização de crianças e adolescentes em inquirições judiciais e violência institucional. Revista Eletrônica Direito e Política, Programa de Pós-Graduação Stricto Sensu em Ciência Jurídica da UNIVALI, Itajaí, v.16, n.1, 10 quadrimestre de 2021. Disponível em: www.univali.br/direitoepolitica - ISSN 1980-7791

Os indicadores das bases de dados do Disque 100, que é o canal da Presidência da República que trata de notificações sobre violações de direitos humanos, e do Sistema de Informação de Agravos de Notificação (SINAN), que especifica os casos de violência identificados no âmbito do Sistema Único de Saúde, vem demonstrando que a violência sexual contra crianças e adolescentes possui ocorrência muito significativa e constante no Brasil, sendo notificados em torno de 183 mil casos de violência sexual infantil no período entre os anos de 2011 à 2014 nas duas entidades analisadas ${ }^{37}$.

Fonte: Ministério da Saúde - SINAN; Secretaria de Direitos Humanos da Presidência da República.

Do universo de casos de violência sexual contra crianças e adolescentes no Brasil, diversos são os casos onde há a busca pela responsabilização criminal de sujeito ativo por meio do Sistema de Justiça a partir de Processos Judiciais, que decorrem de condutas tipificadas como crime no Código Penal e no Estatuto da

\footnotetext{
${ }^{37}$ MINISTÉRIO DA SAÚDE. Sistema de Informação de Agravo de Notificação: Violência Sexual segundo faixa etária e sexo. 2018. Disponível em: http://www2.datasus.gov.br/DATASUS/index.php?area=0203\&id= 29892332\&VObj=http://tabnet.datasus.gov.br/cgi/deftohtm.exe?sinannet/cnv/viole. Acesso em: 22 Mar. 2020.
} 
VIANA CUSTÓDIO, André; DA ROSA MOREIRA, Rafael Bueno. Revitimização de crianças e adolescentes em inquirições judiciais e violência institucional. Revista Eletrônica Direito e Política, Programa de Pós-Graduação Stricto Sensu em Ciência Jurídica da UNIVALI, Itajaí, v.16, n.1, 10 quadrimestre de 2021. Disponível em: www.univali.br/direitoepolitica - ISSN 1980-7791

Criança e do Adolescente. As condutas previstas como crime visam cumprir com a esfera da responsabilização criminal dos violadores de direitos relacionados a dignidade e liberdade sexual de crianças e adolescentes.

Os casos de violência sexual contra crianças e adolescentes são informados ou verificados pelos órgãos executores de políticas públicas que possuem a obrigatoriedade de notificação compulsória do fato. Cabendo ao Conselho Tutelar a responsabilidade de proteção imediata da criança e do adolescente. A partir da identificação da violência sexual, há a busca pela restituição de direitos, o tratamento dos danos causados e a busca pela responsabilização dos agressores.

É na fase judicial, onde se busca a responsabilização dos agressores, que ocorre a inquirições de crianças e adolescentes e o procedimento de revitimização, podendo ser potencializada as ações por atos de violência de cunho moral e institucional cometidos por entes públicos, o que podem causar humilhação e constrangimento a partir de agressões verbais que já foram registradas em casos fáticos que decorrem do abuso de autoridade. Tais violências ocorrem no momento da inquirição, pelos mais diversos motivos, incluindo a troca da versão para o caso a partir de circunstâncias relacionadas a pressão familiar na tentativa de proteção do ofensor em razão dos laços familiares e da culpabilização da vítima pela prisão do agressor quando da violência sexual intrafamiliar.

O respeito pelo outro (pela diversidade) é base conceitual mais expressiva da teoria humanitária que demanda, por assim dizer, uma ação (comissão) em prol e em busca do outro, e, não, diversamente, uma atitude passiva de "suportar" o outro. O respeito, assim, pode muito bem significar o compromisso que se assume em prol da humanidade pelo outro, isto é, a responsabilidade pelo outro. Pois a humanização das relações intersubjetivas deve ser estabelecidas pela perspectiva respeitosa e responsável pelo outro que também (re)significa o eu. Por isso mesmo, a importância da inscrição do marco fundamental não só na constituição conceitual de um valor em si, mas, principalmente, a categoria que o engendra, aquilo que 0 concerne, aquilo que the diz respeito ${ }^{38}$.

38 RAMIDOFF, Mário Luiz. Direito da Criança e do Adolescente: por uma propedêutica jurídico-protetiva transdiciplinar. 2007. 416 f. Tese (Doutorado em Direito), Programa de Pós-Graduação em Direito, Universidade Federal do Paraná, Curitiba, 2007, p. 265-266. 
VIANA CUSTÓDIO, André; DA ROSA MOREIRA, Rafael Bueno. Revitimização de crianças e adolescentes em inquirições judiciais e violência institucional. Revista Eletrônica Direito e Política, Programa de Pós-Graduação Stricto Sensu em Ciência Jurídica da UNIVALI, Itajaí, v.16, n.1, 10 quadrimestre de 2021. Disponível em: www.univali.br/direitoepolitica - ISSN 1980-7791

O preparo técnico não é regra no serviço público, sendo identificados casos onde a revitimização e a violência ocorreram com a anuência dos representantes do Poder Judiciário e da Promotoria de Justiça, por meio de ações ou omissões, em decorrência de que não havia razões para a realização da inquirição em vista de que já haviam provas técnicas suficientes para comprovar o fato, necessitandose somente de conclusão da realização da perícia. Nesses casos, a audiência serve tão somente para que as crianças e adolescentes relembrem do fato, sendo revitimizada, e em algumas das vezes agredida pelo representante institucional que deveria exercer a garantia dos seus direitos. Ou seja, a inquirição da vítima de violência sexual tem ocorrido até mesmo quando injustificada nos casos, onde já houve a sua esculta no momento do inquérito policial ou quando existem outras provas significativas.

Os trâmites processuais penais utilizam de um conservadorismo exacerbado em torno da desconsideração de outros instrumentos de provas e supervalorização da prova testemunhal em quase totalidade dos casos. Acontece que a inquirição da criança ou adolescente vítima de violência sexual gera prejuízos para o seu desenvolvimento integral devido a exposição da vítima a nova forma de violência que reforça o dano psíquico em vista de que se revive a situação traumática anterior, havendo desimportância em relação aos sentimentos de angústia, sofrimento, dor, medo e culpa que acompanham tais lembranças e não são consideradas por parte de muitos dos executores do processo judicial que só pensam em produzir provas para a acusação e elevação de indicadores de condenação. Enquanto a primeira violência é de natureza sexual, a segunda tem caráter psicológico ${ }^{39}$.

Inquirir a vítima, quando criança, ainda que se valendo de novos métodos, como o depoimento sem dano [...], como o intuito de produzir prova e elevar os índices de condenação, não assegura a credibilidade pretendida, além de expor a criança a nova forma de violência, ao permitir que reviva a situação traumática, reforçando o dano psíquico produzido pelo abuso. Enquanto a primeira violência foi de origem sexual, a segunda passa a ser psíquica, na medida em que se espera que a materialidade, que deveria ser produzida

39 AZAMBUJA, Maria Regina Fay de. Inquirição da Criança Vítima de Violência Sexual: Proteção ou Violação de Direitos. Porto Alegre: Livraria do Advogado, 2011, p. 211-212. 
VIANA CUSTÓDIO, André; DA ROSA MOREIRA, Rafael Bueno. Revitimização de crianças e adolescentes em inquirições judiciais e violência institucional. Revista Eletrônica Direito e Política, Programa de Pós-Graduação Stricto Sensu em Ciência Jurídica da UNIVALI, Itajaí, v.16, n.1, 10 quadrimestre de 2021. Disponível em: www.univali.br/direitoepolitica - ISSN 1980-7791

por peritos capacitados, venha ao bojo dos autos por meio do seu depoimento, sem qualquer respeito a suas condições de imaturidade ${ }^{40}$.

Evidencia-se o despreparo em razão da falta de sensibilidade e capacitação de executores do processo judicial nos crimes onde crianças e adolescentes são vítimas de violência sexual. Em casos específicos, até mesmo a educação e o bom senso em relação ao trato com os demais cidadãos são deixados de lado. $\mathrm{Na}$ verdade, a melhor estratégia seria a não realização de inquirição de crianças e adolescentes na maior parte dos casos, pois já existem provas suficientes no momento da audiência, até porque ela já havia sido escultada anteriormente no inquérito policial e podem existir provas periciais robustas especialmente em casos onde haverá exame de material genético. Certamente, a violência vivenciada por ocasião da audiência trará mais traumas ao desenvolvimento integral durante à infância, esquecendo-se da condição de sujeito de direitos própria de todo o ser humano.

Nos casos em comento ocorrem paradoxos, pois grande parte dos entes que possuem a responsabilidade de proteger os direitos da criança e do adolescente, de acordo com a legislação em vigor, são justamente quem realizam a violência. Primeiramente, quando da violência sexual intrafamiliar, os próprios entes da família. Os representantes do Estado que revitimizam, e que, em casos específicos, submetem a tratamento humilhante, agressivo e desrespeitoso pelo discurso verbal e falta de preparação para tratar com uma criança ou adolescente que violam direitos a partir do abuso de autoridade.

Não se deve olvidar que mesmo as hipóteses de depoimento sem dano previstos na Lei n. 13.431/2017, há alguma revitimização em decorrência do relembrar a violência e que pode ser agravado face ao despreparado dos operadores do direito na condução de processos com crianças e adolescentes ${ }^{41}$.

40 AZAMBUJA, Maria Regina Fay de; FERREIRA, Maria Helena Mariante. Aspectos Jurídicos e Psíquicos da Inquirição da Criança Vítima. In: AZAMBUJA, Maria Regina Fay de; FERREIRA, Maria Helena e Colaboradores. Violência Sexual Contra Crianças e Adolescentes. Porto Alegre: Artmed, 2011, p. 58.

41 BRASIL. Lei 13.431. 2017. Disponível em: http://www.planalto.gov.br/ccivil_03/_Ato20152018/2017/Lei/L13431.htm. Acesso em: 27 fev. 2020. 
VIANA CUSTÓDIO, André; DA ROSA MOREIRA, Rafael Bueno. Revitimização de crianças e adolescentes em inquirições judiciais e violência institucional. Revista Eletrônica Direito e Política, Programa de Pós-Graduação Stricto Sensu em Ciência Jurídica da UNIVALI, Itajaí, v.16, n.1, 10 quadrimestre de 2021. Disponível em: www.univali.br/direitoepolitica - ISSN 1980-7791

Dos atos especificados, surtem violações de direitos em decorrência de violência psicológica e institucional a uma vítima de violência sexual, caracterizando-se a revitimização. Expressa a Lei 13.431/17, no seu artigo 40, incisos II, alínea "a", e IV, os conceitos de:

[...] II - violência psicológica:

a) qualquer conduta de discriminação, depreciação ou desrespeito em relação à criança ou ao adolescente mediante ameaça, constrangimento, humilhação, manipulação, isolamento, agressão verbal e xingamento, ridicularização, indiferença, exploração ou intimidação sistemática (bullying) que possa comprometer seu desenvolvimento psíquico ou emocional; $[\ldots]$

IV - violência institucional, entendida como a praticada por instituição pública ou conveniada, inclusive quando gerar revitimização $[\ldots]^{42}$.

Destaca-se que a necessidade de ações de capacitação e formação continuada para os agentes públicos que exercem funções de proteção aos direitos de crianças e adolescentes visando a atuação correta e com a sensibilidade que demanda a área, cumprindo-se com o que é previsto no Estatuto da Criança e do Adolescente, em seu art. 70-A, inciso III ${ }^{43}$.

No Plano Nacional de Enfrentamento da Violência Sexual Contra Crianças e Adolescentes, em seu eixo Defesa e Responsabilização, estão previstas ações que orientam o desenvolvimento de políticas públicas de enfrentamento da violência sexual no panorama brasileiro. Comprometeu-se a desenvolver, nas ações 12 e 13, iniciativas que visem a capacitação dos profissionais de segurança e justiça responsáveis pela realização da escuta de crianças e adolescentes em situação de abuso e/ou exploração sexual, no sentido de evitar que ocorra a revitimização. Assim como, de verificar, antes de qualquer ato, se há a imprescindibilidade da inquirição, realizando-a somente em última circunstância e mediante completa necessidade ${ }^{44}$.

\footnotetext{
42 BRASIL. Lei 13.431. 2017.

43 BRASIL. Estatuto da Criança e do Adolescente.

44 BRASIL. Plano Nacional de Enfrentamento da Violência Sexual Contra Crianças e
}

Adolescentes. Brasília: CONANDA, 2013. 
VIANA CUSTÓDIO, André; DA ROSA MOREIRA, Rafael Bueno. Revitimização de crianças e adolescentes em inquirições judiciais e violência institucional. Revista Eletrônica Direito e Política, Programa de Pós-Graduação Stricto Sensu em Ciência Jurídica da UNIVALI, Itajaí, v.16, n.1, 10 quadrimestre de 2021. Disponível em: www.univali.br/direitoepolitica - ISSN 1980-7791

É fundamental a capacitação para o exercício de atividades de proteção aos direitos da criança e do adolescente, especialmente otimizando os ensinamentos para lidar com as vítimas, evitando-se práticas de violência institucional e psicológica que são próprios de atos de revitimização, o que aumentaria os traumas e as violações de direitos. O investimento em capacitações e treinamentos continuados são necessários em prol do desenvolvimento integral da infância, proporcionando exercício adequado ao Sistema de Garantia de Direitos de Crianças e Adolescentes e do Sistema Judicial no intuito de que não haja a violação de direitos. Dessa forma, cumpriria-se com a proteção jurídica estabelecida nacional e internacionalmente, o que vem sendo buscado por ações de políticas públicas planejadas expressamente nos documentos de enfrentamento da exploração sexual comercial contra crianças e adolescentes no Brasil.

\section{CONSIDERAÇÕES FINAIS}

Constatou-se que o enfrentamento da violência sexual contra crianças e adolescentes está embasado no marco teórico da proteção integral. No Brasil está consolidado o ordenamento jurídico protetivo para garantir direitos humanos e fundamentais de crianças e adolescentes, havendo bases jurídicas que sustentam ações de políticas públicas contra a violência sexual na Constituição da República Federativa do Brasil, na Convenção sobre Direitos da Criança da Organização das Nações Unidas, na Convenção 182 da Organização Internacional do Trabalho e no Estatuto da Criança e do Adolescente.

O contexto de violência sexual assola crianças e adolescentes no Brasil, o que demanda investimento em políticas públicas intersetoriais de enfrentamento a tais práticas, atentando para os compromissos internacionais ratificados pelo país e cumprindo com a legislação nacional. O investimento em políticas públicas é no sentido de estruturar ações estratégicas de proteção, atendimento, promoção de direitos e justiça, assim como de capacitação profissional e sensibilização para atuação de forma adequada e que respeite o desenvolvimento integral durante o período da infância. 
VIANA CUSTÓDIO, André; DA ROSA MOREIRA, Rafael Bueno. Revitimização de crianças e adolescentes em inquirições judiciais e violência institucional. Revista Eletrônica Direito e Política, Programa de Pós-Graduação Stricto Sensu em Ciência Jurídica da UNIVALI, Itajaí, v.16, n.1, ${ }^{\circ}$ quadrimestre de 2021. Disponível em: www.univali.br/direitoepolitica - ISSN 1980-7791

Por fim, assevera-se que crianças e adolescentes vítimas de violência sexual possuem seus direitos violados a partir de um processos de revitimização oriundo da obrigatoriedade de sua inquirição como testemunha no processo judicial, consolidando-se também práticas de violência institucional e psicológica, que levam a rememorar os fatos traumáticos quando de ações arbitrárias, insensíveis e descapacitadas em muitos dos processos judiciais de responsabilização criminal dos agressores. Enfim, crianças e adolescentes em casos concretos tendem a sofrer a violência sexual intrafamiliar, decorrente dos atos, violência psicológica, a partir dos danos decorrentes do caso e de sua revitimização devido da inquirição da forma que foi realizada, e violência institucional, em decorrência de agressões que podem ser sofridas a partir do abuso de poder do operador do direito.

\section{REFERÊNCIAS DAS FONTES CITADAS}

AZAMBUJA, Maria Regina Fay de. Inquirição da Criança Vítima de Violência Sexual: Proteção ou Violação de Direitos. Porto Alegre: Livraria do Advogado, 2011.

AZAMBUJA, Maria Regina Fay de; FERREIRA, Maria Helena Mariante. Aspectos Jurídicos e Psíquicos da Inquirição da Criança Vítima. In: AZAMBUJA, Maria Regina Fay de; FERREIRA, Maria Helena e Colaboradores. Violência Sexual Contra Crianças e Adolescentes. Porto Alegre: Artmed, 2011.

BOBBIO, Norberto. O futuro da democracia. Traduzido por: Marco Aurélio Nogueira. Rio de Janeiro: Paz e Terra, 1999.

BRASIL. Constituição da República Federativa do Brasil. 1988. Disponível em: http://www.planalto.gov.br/ccivil_03/constituicao/constitui\%C3\%A7ao.htm. Acesso em: 25 fev. 2020.

BRASIL. Estatuto da Criança e do Adolescente. 1990. Disponível em: http://www.planalto.gov.br/ccivil_03/leis//8069compilado.htm. Acesso em: 25 fev. 2020.

BRASIL. Lei $13.431 .2017 . \quad$ Disponível em: http://www.planalto.gov.br/ccivil_03/_Ato2015-2018/2017/Lei/L13431.htm. Acesso em: 27 fev. 2020.

BRASIL. Plano Nacional de Enfrentamento da Violência Sexual Contra Crianças e Adolescentes. Brasília: CONANDA, 2013. 
VIANA CUSTÓDIO, André; DA ROSA MOREIRA, Rafael Bueno. Revitimização de crianças e adolescentes em inquirições judiciais e violência institucional. Revista Eletrônica Direito e Política, Programa de Pós-Graduação Stricto Sensu em Ciência Jurídica da UNIVALI, Itajaí, v.16, n.1, 10 quadrimestre de 2021. Disponível em: www.univali.br/direitoepolitica - ISSN 1980-7791

BUSTELO, Eduardo S. El recreo de la infancia: Argumentos para otro comienzo. Buenos Aires: Siglo Veintiuno Editores, 2011.

CUSTÓDIO, André Viana; MOREIRA, Rafael Bueno da Rosa. Exploração Sexual Comercial de Crianças e Adolescentes: Reflexões Contemporâneas no Contexto do Brasil, da Argentina e do Uruguai. Curitiba: Multideia, 2015.

CUSTÓDIO, André Viana. Teoria da proteção integral: pressupostos para a compreensão do direito da criança e do adolescente. Revista do Direito: Revista do programa de pós-graduação do mestrado e doutorado, Santa Cruz do Sul, n. 29, p. 22-43, jan-jun. 2008.

CUSTÓDIO, André Viana; VERONESE, Josiane Rose Petry. Trabalho Infantil Doméstico. São Paulo: Saraiva, 2013.

GUERRA, Viviane $\mathrm{N}$. de Azevedo. Violência de pais contra filhos: A tragédia revisitada. São Paulo: Cortez, 2001.

LAPIERRE, Jean-William. Qué es ser ciudadano. Madrid: Biblioteca Nueva, 2003.

LIMA, Fernanda da Silva. Crise humanitária internacional e os direitos das crianças migrantes ou refugiadas: uma análise da opinião consultiva no 21 da Corte Interamericana de Direitos Humanos. Revista do Direito: Revista do Programa de Pós-graduação do Mestrado e Doutorado, Santa Cruz do Sul, v.1, n. 51, p. 87-107, jan./abr. 2017.

MARSHALL, T.H. Cidadania, classe social e status. Zahar Editores: Rio de Janeiro, 1967.

MINISTÉRIO DA SAÚDE. Sistema de Informação de Agravo de Notificação: Violência Sexual segundo faixa etária e sexo. 2018. Disponível em: http://www2.datasus.gov.br/DATASUS/index.php?area=0203\&id=

29892332\&VObj=http://tabnet.datasus.gov.br/cgi/deftohtm.exe?sinannet/cnv/vi ole. Acesso em: 22 Mar. 2020.

MORIN, Edgar. A cabeça bem-feita: repensar a reforma, reformar o pensamento. Rio de Janeiro: Bertrand Brasil, 2001.

ONU. Convenção sobre os Direitos das Crianças. 1989. Disponível em: http://www.planalto.gov.br/ccivil_03/decreto/1990-1994/D99710.htm. Acesso em: 26 fev. 2020.

OIT. Convenção 182 sobre a proibição das piores formas de trabalho infantil e ação imediata para sua eliminação. 1999. Disponível em: http://www.ilo.org/public/spanish/standards/relm/ilc/ilc87/com-chic.htm. Acesso em: 26 fev. 2020.

RAMIDOFF, Mário Luiz. Direito da Criança e do Adolescente: por uma 
VIANA CUSTÓDIO, André; DA ROSA MOREIRA, Rafael Bueno. Revitimização de crianças e adolescentes em inquirições judiciais e violência institucional. Revista Eletrônica Direito e Política, Programa de Pós-Graduação Stricto Sensu em Ciência Jurídica da UNIVALI, Itajaí, v.16, n.1, ${ }^{\circ}$ quadrimestre de 2021. Disponível em: www.univali.br/direitoepolitica - ISSN 1980-7791

propedêutica jurídico-protetiva transdiciplinar. 2007. 416 f. Tese (Doutorado em Direito), Programa de Pós-Graduação em Direito, Universidade Federal do Paraná, Curitiba, 2007.

REIS, Suzéte da Silva. Educação em Direitos Humanos: Perspectivas de promoção e defesa dos direitos das crianças e adolescentes. In: PES, João Hélio Ferreira (coordenador). Direitos Humanos: Crianças e Adolescentes. Curitiba: Juruá, 2010.

SECRETARIA DE DIREITOS HUMANOS DA PRESIDÊNCIA DA REPÚBLICA. Balanço Geral de Denúncias do Disque 100: Crianças e Adolescentes (20112016). 2016. Disponível em: http://www.sdh.gov.br/disque100/balanco-2016completo Acesso em: 22. Mar. 2020.

VERONESE, Josiane Rose Petry. O Estatuto da Criança e do Adolescente: Um Novo Paradigma. In: VERONESE, Josiane Rose Petry; ROSSATO, Luciano Alves; LÉPORE, Paulo Eduardo (Coordenadores). Estatuto da Criança e do Adolescente: 25 anos de desafios e conquistas. São Paulo: Saraiva, 2015.

RECEBIDO EM: FEV/2020

APROVADO EM: AGO/2020 